\title{
Impacts of Social Learning (SL) on Paragraph Writing Skills
}

\author{
Wondwosen Tesfamichael Ali \\ Department of English Language \& Literature, Faculty of Social Science \& Humanities, Wolaita Sodo University, Wolaita Sodo, Ethiopia \\ Email address: \\ wondutesfa@gmail.com \\ To cite this article: \\ Wondwosen Tesfamichael Ali. Impacts of Social Learning (SL) on Paragraph Writing Skills. Science Research. \\ Vol. 6, No. 1, 2018, pp. 15-23. doi: 10.11648/j.sr.20180601.13
}

Received: November 20, 2017; Accepted: November 28, 2017; Published: February 6, 2018

\begin{abstract}
This quasi-experimental study probed the effects of implementing SL on paragraph writing skills in terms of content, vocabulary, grammar, and mechanics. The participants of the study were grade 11 students at Yekatit 12 Preparatory School, Ethiopia. The experimental group was taught paragraph writing skills in line with the principles of SL. The control group was taught similar paragraph writing skills through the traditional method in which SL was not effectively implemented. Pre- and post-tests were used on paragraph writing tasks. The data were analyzed using descriptive and inferential statistics. In addition, the selected participants from the experimental group were interviewed. Their responses were recorded and analyzed qualitatively to learn their feelings about the effects of implementing SL in an EFL (English as a Foreign Language) class. The results of the study after the intervention indicated that the experimental group significantly outscored the control group $(p<0.05)$ on a paragraph writing post-test with regard to content, vocabulary, grammar, and mechanics. The focus group discussion results also showed that the experimental group participants preferred to use an appropriate implementation of SL than the traditional implementation of SL. Finally, it was concluded that implementing SL in an EFL class helped the experimental group participants compose better paragraphs in terms of content, vocabulary, grammar, and mechanics. On the basis of the findings and conclusions, a painstaking employment of social skills during paragraph writing stages was suggested as a pedagogical implication.
\end{abstract}

Keywords: Social Skills, Paragraph Writing, Traditional Method, EFL (English as a Foreign Method), Ethiopia

\section{Introduction}

Recent studies in the field of language teaching accentuate the importance of the learning process and the central role of students [Leila, 2010]. This situation is realized, among other things, when students are provided opportunities to learn socially. In this regard, Richards and Rodgers [2001] contend that traditional learning methods, which do not focus on the learning process and the central role of students, is a teacherfronted approach that fosters competition rather than cooperation. This is because, $70 \%$ of the class time is being used by the teacher while the students are sitting and listening passively [Cuban, 1983]. Rutherford and Stuart [1978] showed that this kind of teaching can lead to a decrease in students' attention as lectures progress. When there is a shift from a teacher-centered to a student-centered approach, teacher talk is generally reduced by around $50 \%$, and the extra time can be spent praising and aiding students in their exchange of ideas.
Thus, in the classrooms where students learn socially, the students remain in charge of their own discoveries and become truly excited about the learning process [Vermette, 1998]. Vygotsky [1978] also emphasized that SL can promote learning because the process of cooperation during learning enables the students to operate within one another's Zones of Proximal Development (ZPD). Working with peers has academic benefits because it enables students to comprehend things more easily than solely listening to an explanation given by a person at a different stage of development than the learners themselves.

Similarly, Hirst and Sinclair [1989] explained that when students or tutees seek out peer help, they receive individualized instruction and more focused teaching; they may also respond better to their peers than their teachers, and they can build relationships with their tutors. Moreover, Krashen and Terrel [1983] indicated that input from SL is likely to be comprehensible and contributes to second or first language learning as group members' language levels may be roughly equal. This, according to Krashen and Terrel, 
facilitates learning which results in higher levels of understanding and reasoning, the development of critical thinking, and a possible increase in the accuracy of long-term retention.

Recognizing the value of SL, the Ethiopian Ministry of Education issued the National Education Policy [1994], which requires teachers to practice group work and studentcentered teaching. Specifically, teachers are asked to implement One-to-Five Learning Method. This is a type of SL method which engages students in working five heterogeneous member groups on a given task to accomplish mutual learning goals.

However, the appropriate implementation of $\mathrm{SL}$ in Ethiopia has encountered several problems. Ambaye [1999] found that many teachers in Ethiopia lack the critical determination of effective teaching; that is, they lack the pedagogical content knowledge and motivation although they are in the front line of education reform programmes. Ambaye further explained that teachers in the current training institutes of Ethiopia predominantly use conventional/traditional types of teaching methods that they are familiar to them perhaps even the ones that they themselves experienced when they were students at schools. Moreover, Marshal [1990] as cited in ICDR [1999] raised educational problems in Ethiopia by saying that teachers use only a small number of methods, typically teachers' talk, question and answer and textbook assignments.

\section{Research Questions}

This study examined the comparisons between the control and experimental groups overall results in paragraph writing, i.e. content, vocabulary, grammar and mechanics, and their perceptions about the implementation of SL in the course of paragraph writing lessons. Thus, the study endeavors to address the following research questions:

1. Is there a statistically significant difference between the mean scores of the control and experimental groups on paragraph writing post-test in terms of content, vocabulary, grammar and mechanics?

2. What do the students' perceptions about the implementation of SL look like while writing paragraphs in English as a foreign language (EFL) class?

\section{Literature Review}

\subsection{Definitions of $S L$}

As to the definition of SL, Dutsch [1962] in Brubacher, et al [1990] said that SL is the instructional use of small groups so that students work together to maximize their own and one another's learning. Within SL, students are given two responsibilities: to learn the assigned material and to make sure that all other members of the group do likewise. Thus, a student seeks an outcome that is beneficial to him/her and beneficial to all other group members.

Moreover, Argyle [1991] as quoted in McConnell
[1994:12] defined SL by saying, "It is acting together in a coordinated way at work or in social relationships, in the pursuit of shared goals, the enjoyment of joint activity, or simply furthering the relationships."

The intent of the definitions given above is that SL is a method in which students with different levels of abilities, attitudes, and backgrounds are active agents in the process of learning through small group structures so that they help each other maximize their own and understanding of a subject. In this study, the researcher studied if the implementation of the independent variable deemphasized competitive and individualistic learning rather than cooperation which encourages the experimental group research participants to work together and become successful in composing paragraphs and exercising social skills as a team in their class.

\subsection{Rationales for Using SL in an EFL Classroom}

To build up the teaching learning process in general, there seems to be an increasing consensus in pedagogy worldwide about the need to shift from a teacher-centered method of teaching (where the teacher does all the talking with students remaining passive) to a SL method (with students actively involved in the learning process) [Nagata \& Ronkowski, 1998].

Creemers [1994] and Moffet [1996] added that SL enables students from a pluralistic society to overcome their prejudices against others from different backgrounds such as culture, learning style, religion, etc. In other words, SL provides students with opportunities to enhance inter-ethnic relations and learn to appreciate differences as their focus of attention is getting immersed when they learn writing or other skills with this method in EFL classrooms.

Slavin [1991], and Stahl and Van Sickle [1992] argued that students found in very diverse school settings and taught a wide range of content areas reveal higher academic test scores, higher self-esteem and positive social skills after completing the tasks treated through SL.

Reticent students also get an opportunity to make new friends and familiarize different activities more easily through this method. Stenlev [2003] pointed out the positive effect of SL by saying that it is a democratic form of learning, i.e. every single student is required in many different contexts to adopt an attitude and explain his or her own point of view. She further explained that students learn social skills like to listen to and respect each other, and every one can feel that they are at the center at the same time. So, according to her, it is an excellent way of conducting communicative language teaching.

Though SL which has, as stated by the authors mentioned above, positive impacts on the teaching learning process, it could be applied to all language skills [Elbow, 2000; Howard, 2000] Stewart [1988] \& Webb [1998] focused on the rationales of incorporating SL into writing skills and explained that the method:

1. Forces the writer to put tacit decisions about his/her writing process into words. 
2. Allows students to learn from each other as confident students will model successful writing practices for struggling students.

3. Allows students to work on complex projects which may otherwise be too large in scope for an individual author to tackle over the course of the semester.

4. Fosters relationships among a community of writers as it takes away the loneliness of the writing act.

5. Focuses on the generation of many possible points of views/solutions to a problem, which ultimately leads to more complex conclusions.

Thus, to make students users of this method, attention should be given to what they can do to initiate and manage their own learning through SL. This is more feasible, according to Ingleton, et al [2000], when teachers organize the groups instead of allowing the students to self-select. In spite of the positive effects of the method in EFL/ESL classes, it has some drawbacks as discussed in the next section.

\subsection{SL Versus Competitive and Individualistic Learning}

Students' learning goals can be structured to promote social, competitive or individualistic efforts. Competitive learning situations are ones in which students work against one another to achieve a goal that only one or a few can attain, whereas in individualistic learning situations, the students work alone to accomplish goals unrelated to classmates, i.e. the students' goal achievements are independent. The result is to focus on self-interest and personal success, and ignore as irrelevant the successes and failures of others [Ames and Ames, 1985].

In contrast to individualistic and competitive learning situations raised above, Johnson and Johnson [1987] explained that social, competitive and individualistic learning methods are important and should be used, but the dominant goal structure in any class should be cooperative/social because competitive and individualistic learning are primarily effective when they are used within a context of cooperation.

Thus, SL which can be created by structuring positive interdependence among learners leads to outcomes. Brubacher, et al [1990:72] described, "Higher achievement, more positive relationship among individuals, greater social support, and higher self-esteem are the outcomes that seem more important than the many outcomes impacted by social efforts." The listed outcomes are also illustrated in the figure given in the next section.

To put in a nutshell, students who are beneficiaries of the illustrated social skills in an EFL class help one another during the process of drafting, planning, translating, and reviewing the writing tasks together, i.e. they can monitor and evaluate the tasks cooperatively. In such class activities, team members try to make sure that each member has mastered the assigned task because the teacher randomly asks them to answer for the team. This kind of learning serves to harness competition for further cooperation amongst members of the teams.

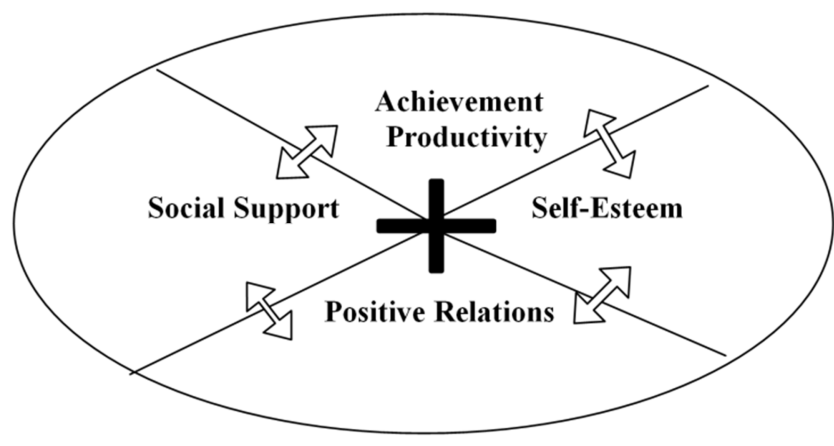

Figure 1. Outcomes of the SL [adapted from Brubacher, et.al, 1990:72].

\subsection{Social Skills}

Students who have never been taught the prerequisite social skills which encompass communicating, trust building, leadership, conflict resolution, group management, giving and receiving feedback, active listening skills, etc. cannot be expected to work together effectively [Johnson, Johnson and Holubec, 1993]. These skills for effective social work do not magically appear when social lessons are employed. Instead, they must be taught to students as purposefully and precisely as academic skills. Schultz [1999] argued that social skills should be explicitly taught to the students so that they could work among themselves, not only in terms of cooperation but also without hostility and without the teacher's authority. However, Johnson and Johnson [1994] warned that placing socially unskilled students in a group and telling them to cooperate does not guarantee that they have the ability to do so effectively.

Kline and Lerner [2006:539] also added, "We are not born knowing instinctively how to interact effectively with others." It is, therefore, necessary that social skills must be taught to students. Westwood [2003] and Christson [1994] shared this idea and focused on the need for direct teaching of social skills like leadership, decision-making, trustbuilding, communication, conflict resolution, group management and other skills. These skills empower the students to manage the SL which is, according to Johnson and Johnson [1994], inherently more complex than competitive or individualistic learning because the students have to engage simultaneously in task work (learning academic subject matter) and teamwork (functioning effectively as a group).

Early teaching of social skills mentioned above may help the students minimize dropping out of schools, poor achievement, delinquency, inattentiveness, peer rejection, aggressiveness, problems in interpersonal relationships, poor self-concept, academic failures, concentration difficulties and isolation from peers [Christopherson, 2003].

\section{Methodology}

Participants in Yekatit 12 Preparatory School, in the 2014 academic year, there were six EFL teachers teaching eleventh graders in 18 different sections. Of these EFL teachers, one was selected randomly and invited to participate in the 
research. The teacher taught two sections of eleventh graders and the participants in the two sections were given a paragraph writing pre-test. 76 students responded appropriately to the pre-test and thus only these were put into the experimental group and the control groups (38 in each group). They use English primarily for academic studies (particularly from grade seven) and learn it as a subject. The experiment was carried out with the agreement of the classroom teacher, students, and the school directors.

\subsection{Tasks and Materials}

\subsubsection{For the Teacher}

The teacher that taught the selected sections was offered training on SL as their awareness of the method might have an impact on the results of the quasi-experimental study. For a week prior to the intervention, the teacher was provided training with the definition of SL, rationales for using SL in an EFL Classroom, SL versus competitive and individualistic learning and Social skills.

The researcher gave the training on the basis of his own knowledge of SL from the literature and experiences teaching EFL classes. For the training, the researcher referred to the following books: Cooperation and Competition: Theory and Research by Johnson \& Johnson [1989]; Enhancing Social Skills through Cooperative Learning by Booysen \& Grosser [2008]; Cooperative Learning: Integrating Theory and Practices by Gillies [2007] and An Experimental Study to Evaluate the Effectiveness of CL versus Traditional Learning Methods by Khan [2008].

\subsubsection{For the Students}

Tests which take many forms provide a way to assess participants' knowledge and capacity to apply this knowledge to new situations. They may require respondents to choose among alternatives, produce short answers, or write extended responses [Guba \& Lincoln, 1981]. Considering Gubaand Lincoln's [1981] ideas, the researcher administered pre- and post-tests for the experimental and control groups to gauge their paragraph writing skills. The paragraph writing tests were adapted from Brenda [1997]. The tests were comprised of four different types of topics and the participants were asked to choose and write on any two topics.

In the pre-test (see Appendix A), students were asked to write a narrative paragraph about their best friend, describe their school, write an expository paragraph about their hobby and write an argumentative paragraph supporting or opposing either of the ideas entitled a gram of chance is better than a kilo of knowledge.

The topics were assumed to be familiar with all the participants as they are related to the participants' day to day lives. Their papers were marked by the researcher. Learners who achieved similar results were randomly assigned into experimental and control groups in their intact classes.

After the pre-test, eight writing tasks meant for practice, in addition to the pre- and post-writing tests, were given to each group at different times. The participants in the experimental group were taught paragraph writing with the lesson plans prepared by the researcher based on Kirk's (2005) ideas given in the next section.

1. It involves the explicit teaching of social skills necessary for group functioning.

2. It emphasizes team-building activities before students begin working together.

3. It should be continuous with the curriculum rather than an isolated add-on and engage students in exploring and applying the content currently being taught.

4. Each group works on the same task simultaneously and pools its resources. Only one completed activity sheet is submitted from the group. Each student within the group makes his/her own verbal/written contribution to the given activity.

5. Students are assigned specific roles (tasks) in order to facilitate the smooth running of the group work.

Participants in the control group, on the other hand, were given the same writing activities via a traditional learning method, which was non-SL. The lesson plans were prepared by the subject teacher based on the textbook and teacher guide. The time given for discussions and composing a paragraph to each group was equal, i.e., 25 minutes for discussions and 15 minutes for composing a paragraph. The experiment was conducted for two months. After the treatment, a paragraph writing post-test (see Appendix B) was administered. The post-test also consisted of four items whose contents were similar to the issues raised in the pretest and the participants were again asked to write on any two topics. The aim of the paragraph writing post-test was to weigh the possible effects on the experimental group's writing after the intervention.

Two teachers with B. A degrees in English corrected each of the groups' compositions. They were asked to rate the students' paragraphs for content, vocabulary, grammar and mechanics on a scale of $0-4$ for each category, making it a total of 20 points for each paragraph. After the two teachers had finished marking the students' papers, the researcher then compared the ratings given by the teachers to each student. When the ratings were similar, they were recorded as the final rating. When there were differences, the researcher took the average of the two ratings. The two teachers' ratings had a correlation of 0.81 for the pre-test. Since this indicated that their ratings had an acceptable degree of agreement.

\subsection{Focus Group Interview}

Six randomly selected participants (two high, two average, and two lower achievers) from the experimental group were interviewed by the researcher (see Appendix C). They were interviewed whether or not the effects of implementing SL helped them improve their paragraph writing in terms of content, vocabulary, grammar, and mechanics; they were asked why they could say 'yes' or 'no' to the question posed. The final question that the researcher raised was if they encountered any problems while writing paragraphs through SL and if their answer was 'yes', they were asked to suggest some solutions in connection with the problems. The focus group interviews were conducted for twenty minutes after the 
paragraph writing post-test had been administered and responses were video recorded to analyze the content validity.

\subsection{Analytical Procedure}

The participants' paragraph writing pre- and post-test results were analyzed using Statistical Package for Social Sciences (SPSS) version 20 for Windows, i.e., their inter- and intra-group comparisons were analyzed through independent and paired samples t-tests respectively.

\section{Findings}

To measure the participants' skills in paragraph writing in terms of content, vocabulary, grammar and mechanics, the results from the pre-test and post-tests were compared. The effect size was measured using Cohen's d index of effect size formula to see how strong the relationship between the variables was [Cohen, 1988]. Coe [2002] and Elis [2010] showed that the difference between two groups is calculated by subtracting the mean of one group from the other (M1M2) and dividing the result by the standard deviation of the population from which the groups were sampled. Moreover, Cohen [1988] showed the degrees of effect sizes as $0-0.20=$ weak, $0.21-0.50=$ modest, $0.51-1.00=$ moderate and $>$ $1.00=$ strong. The results and analyses of the tests are provided in the next section.

Table 1. Independent Samples T-Test Results of the Control and Experimental Groups on Paragraph Writing Post-Test $(N=78)$.

\begin{tabular}{lllllll}
\hline Groups & Mean & SD & Std. Error Mean & t & df & Sig. (2-tailed) \\
\hline Control & .67 & 3.60 & .577 & -.758 & 76 & $2.451^{*}$ \\
Experimental & 9.23 & 2.94 & .471 & 76 & \\
\hline
\end{tabular}

$* \mathrm{p}<0.05$.

Table 1 depicts that the control and experimental groups obtained different mean scores on paragraph writing posttest. The mean score of the control group is less than the mean score of the experimental group. Moreover, the table denotes the difference between the mean scores of the intergroups on paragraph writing post-test. The paragraph writing post-test mean scores $(\mathrm{t}=-3.260, \mathrm{df}=76, \mathrm{p}=.002)$ reveal that there is a statistically significant difference between the mean gain scores of the control and experimental groups on paragraph writing post-test at 0.05 alpha level, favoring the latter. Moreover, the effect size, which is 0.74 , shows that the magnitude of the difference between the control and experimental groups in achieving paragraph writing post-test is moderate. This might have happened because of the treatment offered to the experimental group research participants.

Table 2. Paired Samples T-Test Results of the Experimental Group on Content, Vocabulary, Grammar and Mechanics Pre-Post-Paragraph Writing Tests $(N=39)$.

\begin{tabular}{|c|c|c|c|c|c|c|c|}
\hline Variables & Tests & Mean & SD & Std. Error Mean & $\mathbf{t}$ & df & Sig. (2- tailed) \\
\hline \multirow{2}{*}{ Content } & Pre & 1.77 & .667 & .107 & \multirow{2}{*}{-6.407} & \multirow{2}{*}{38} & \multirow{2}{*}{$.000^{*}$} \\
\hline & Post & 2.82 & .791 & .127 & & & \\
\hline \multirow{2}{*}{ Vocabulary } & Pre & 1.92 & .839 & .134 & \multirow{2}{*}{-3.229} & \multirow{2}{*}{38} & \multirow{2}{*}{$.003 *$} \\
\hline & Post & 2.51 & .791 & .127 & & & \\
\hline \multirow{2}{*}{ Grammar } & Pre & 1.74 & .751 & .120 & \multirow{2}{*}{-3.137} & \multirow{2}{*}{38} & \multirow{2}{*}{$.003^{*}$} \\
\hline & Post & 2.23 & .706 & .113 & & & \\
\hline \multirow{2}{*}{ Mechanics } & Pre & 1.59 & .637 & .102 & \multirow{2}{*}{-4.025} & \multirow{2}{*}{38} & \multirow{2}{*}{$.000 *$} \\
\hline & Post & 2.26 & .785 & .126 & & & \\
\hline
\end{tabular}

$* \mathrm{P}<0.05$.

Table 2 reveals the mean scores of the paragraph writing pre-post-results of the experimental group. The experimental group's mean scores on content, vocabulary, grammar and mechanics of paragraph writing pre-test are 1.77, 1.92, 1.74, and 1.59 , respectively. On the other hand, its mean scores on the same components of paragraph writing post-test are 2.82, $2.51,2.23$ and 2.26, respectively. So, the results in the post-test are greater than that of the pre-test. This implies that the participants showed improvement in paragraph writing after the intervention. The standard deviations of the experimental group's paragraph writing pre-test in terms of content, vocabulary, grammar and mechanics are.667,.839,.751 and.637, respectively whereas the standard deviations of its paragraph writing post-test in terms of the same components are.791,.791,.706 and.785. This shows that the mean scores of the experimental groups are different from the control group.

Moreover, the paired samples $t$-test results $(\mathrm{t}=-6.407, \mathrm{df}=$
$38, \mathrm{p}=.000 ; \mathrm{t}=-3.229, \mathrm{df}=38, \mathrm{p}=.003 ; \mathrm{t}=-3.137, \mathrm{df}=38, \mathrm{p}=.003$ and $\mathrm{t}=-4.025, \mathrm{df}=38, \mathrm{p}=.000$ ) show that the experimental group made a significant progress in paragraph writing posttest in terms of the said components. That is to say, the mean scores of the experimental group's paragraph writing posttest are higher than that of the mean scores of its pre-test in terms of content, vocabulary, grammar and mechanics. Thus, the comparison of the mean scores obtained by the experimental group indicates that there are statistically significant differences between the mean scores of the experimental group on pre-post-tests in terms of the listed components at 0.05 alpha levelfavoring the post-test. The effect sizes of the content, vocabulary, grammar and mechanics are $1.44,0.72,0.67$ and 0.94 , respectively, which show that the differences in achieving both tests in terms of the said components by the experimental group research participants are strong and moderate. 
Table 3. Paired Samples T-Test Results of the Control Group on Paragraph Writing Pre-Post-Tests in Terms of Content, Vocabulary, Grammar and Mechanics $(N=39)$.

\begin{tabular}{|c|c|c|c|c|c|c|c|}
\hline Variables & Tests & Mean & SD & Std. Error Mean & $\mathrm{t}$ & df & Sig. (2 tailed) \\
\hline \multirow{2}{*}{ Content } & Pre & 1.95 & .793 & .127 & \multirow{2}{*}{-.393} & \multirow{2}{*}{38} & \multirow{2}{*}{$.696^{*}$} \\
\hline & Post & 2.03 & .843 & .135 & & & \\
\hline \multirow{2}{*}{ Vocabulary } & Pre & 1.97 & .959 & .154 & \multirow{2}{*}{-.467} & \multirow{2}{*}{38} & \multirow{2}{*}{$.643 *$} \\
\hline & Post & 2.08 & .839 & .134 & & & \\
\hline \multirow{2}{*}{ Grammar } & Pre & 1.64 & .932 & .149 & \multirow{2}{*}{-.473} & \multirow{2}{*}{38} & \multirow{2}{*}{$.639 *$} \\
\hline & Post & 1.74 & .818 & .131 & & & \\
\hline \multirow{2}{*}{ Mechanics } & Pre & 1.54 & .790 & .126 & \multirow{2}{*}{-.598} & \multirow{2}{*}{38} & \multirow{2}{*}{$.553^{*}$} \\
\hline & Post & 1.64 & .628 & .101 & & & \\
\hline
\end{tabular}

$* \mathrm{P}>0.05$.

Table 3 indicates that the mean scores of the control group on paragraph writing pre-post-tests in terms of content, vocabulary, grammar and mechanics are slightly different. As can be seen in the table, the participants' mean scores of the pre-test in connection with the listed components of writing skills are $1.95,1.97,1.64$ and 1.54 , respectively whereas the mean scores of the post-test for the said components are 2.03, 2.08, 1.74 and 1.64, respectively. According to the table, the standard deviations of paragraph writing post-test are almost slightly lower than that of the pre-test. This discloses the presence of a gap in the students' post-test scores.

As in table 5.3, $\mathrm{t}=-.389, \mathrm{df}=38, \mathrm{p}=.696 ; \mathrm{t}=-.467, \mathrm{df}=38$, $\mathrm{p}=.643 ; \mathrm{t}=-.473, \mathrm{df}=38, \mathrm{p}=.639$ and $\mathrm{t}=-.598, \mathrm{df}=38, \mathrm{p}=.553$ reveal that there is no significant difference between the mean scores of paragraph writing pre-post-tests of the control group at 0.05 level. The results, thus, show that the control group research participants have not shown any significant difference in their paragraph writing skills in the post-test. The effect sizes of content, vocabulary, grammar and mechanics of paragraph writing skills are $0.09,0.12,0.11$ and 0.14 which show that the differences in the mean scores of pre-post-tests of paragraph writing are trivial.

\section{Results of the Students' Focus Group Discussion}

As responded by the experimental group research participants, they liked learning paragraph writing tasks through the SL since it rendered them develop their vocabularies, scrutinize different notions forwarded by team members and practice delivering speeches before their team members and the class.

The second question that the informants were asked was how the SL would help them mitigate their paragraph writing skills. They said that the method, of course, helped them improve paragraph writing skills. It enabled them to generate as many ideas as possible in line with the given writing tasks and share the notions among ourselves to produce paragraphs written in appropriate grammatical sentences.

The next question raised by the interviewer was that how the respondents got the participation of each member in their teams while learning writing via the SL. In response to this question, the informants said that at the very beginning of the discussions, they were afraid of forwarding ideas that lingered in their minds as they felt that they were laughed at, but later on they felt free to raise as many notions as possible and debated each other on the raised issues, and finally came to terms peacefully.

"What type/s of problems have you encountered while practicing paragraph writing through SL?" was the other question that the interviewees were asked. Concerning this question, the interviewees answered theydid not almost face problems but accountability in relation to their writing tasks was most of the time offered to team leaders by ignoring the rest members of the team.

Finally, the respondents were asked to forward their suggestions for the betterment of the SL. They suggested that they wanted to learn some other subjects with this method. The teacher should also encourage students to express their ideas in English rather than in Amharic. Indeed, Abiy's [2012] research finding indicated that L1 use at pre-writing stage helps participants produce better content during their writing in an L2. Moreover, members in each team had to be entrusted fairly when they discussed writing activities in teams.

\section{Discussions}

This study shows that there was a statistically significant difference between the mean scores of both groups on paragraph writing post-test in terms of content, vocabulary, grammar, and mechanics at 0.05 alpha level. This difference occurred possibly because the method used by the experimental group during the intervention was more effective than that of the control group in developing these skills. Students also seemed to have positive reaction to the SL.

The findings show that the SL resulted in significantly positive outcomes after it had been implemented to teach paragraph writing skills. The participants in this study gained the benefits of the method and improved their paragraph writing skills. These findings are consistent with the previous research conducted by Adeyemi [2008], whose research revealed that there was a statistically significant increase in writing skills with the experimental group after implementing the SL in a writing class.

Furthermore, the findings seem to be in agreement with 
Sirikhun [2000]. His study shows improvements in student achievement after learning writing skills through SL. He indicates that the students performed better in the post-test as compared to the pre-test after the inclusion of SL in the writing class. The experimental group participants outperformed the control group participants on the paragraph writing post-test perhaps because they practiced composing different paragraphs via SL. The method created more frequent interactive and supportive learning environments within which the learners had the chance to ask questions, organize ideas, and decide the best concepts to help them produce better compositions.

The interviewees in the experimental group witnessed that employing SL was a great help for them in composing better paragraphs in terms of the investigated components. Their responses also support the statistical findings reported earlier. Socio-cultural theorists have suggested that when students perform a given task socially, they can operate within one another's zone of proximal development [Vygotsky, 1978]. The social interdependent theorist Lewin [1948] also argued that SL encourages students to help their classmates succeed, contrary to competitive and individualistic learning methods. To this end, group members encourage other group members to exert a maximum amount of effort in their learning. This kind of learning among the participants in the experimental group enabled them to augment their paragraph writing skills in terms of content, vocabulary, grammar, and mechanics.

\section{Conclusions}

Based on the statistical analyses and descriptions of the findings of this study, the following conclusions are made.
The paragraphs writing post-test results analyzed through independent samples t-tests indicate that the experimental group significantly surpassed the control group. This occurred because the research participants in the experimental group were made to practice paragraph writing through the SL. So, the experimental group participants were observed when they interacted frequently based on SL that they had been taught while working on the writing activities in their heterogeneous groups. Thus, the null hypothesis that was stated as there is no statistically significant difference between the mean scores of the experimental and control groups on paragraph writing post-test regarding content, vocabulary, grammar and mechanics was discarded as the difference between the mean scores of the inter-groups was significant at 0.05 alpha level.

On the whole, the SL which was implemented in line with the literature has given opportunities to the experimental group research participants to review what they had written together, i.e. peer criticism aids students sharpen their knowledge about paragraph structure and grammatical rules. It also provides the students with the chance of evaluating their own work, demonstrating more confidence in writing and decreasing their apprehensions towards learning writing skills.

According to the responses of the focus group interviews, learning through the SL would be equally interesting both for the teacher and the students. The students working with partners ask each other for help and improve their achievements in writing and social skills. Thus, an appropriate implementation of this method in EFL classes will be of great benefit to the students to boost their writing skills.

\section{Appendix}

\section{Appendix $A$}

\section{Bahir Dar University}

Department of English Language and Literature

Paragraph Writing Pre-test for Eleventh Graders

Time Allotted 50'

Total Mark: 20

Directions

This is a paragraph writing test which is intended to examine your skills in writing narrative, descriptive, expository and argumentative paragraphs. Hence, of the give four options, choose any two and write them with legible handwriting.

1. Write a narrative paragraph about your best friend.

\section{Describe your school.}

3. Write an expository paragraph about your hobby.

4. A gram of chance is better than a kilo of knowledge. Write an argumentative paragraph supporting or opposing either of the ideas 


\section{Appendix $B$}

Bahir Dar University

Department of English Language and Literature

Paragraph Writing Post-Test for Eleventh Graders

Time Allotted: 50'

Total Mark: 20

Directions

This is a paragraph writing test which is intended to examine your skills in writing narrative, descriptive, expository and argumentative paragraphs. Hence, of the give four options, choose any two and write them with legible handwriting.

1. Write a narrative paragraph about your best vacation.

2. Describe your classroom.

3. Write an expository paragraph about a sport that you like.

4. Ethiopia should follow a one-child policy like China. Write an argumentative paragraph either oppo- sing or supporting the motion.

\section{Appendix C}

Focus Group Interview for the Research Participants in the Experimental Group

1. Do you like learning paragraph writing through SL? Why or why not?

2. Do you think that the SL helped you improve paragraph writing skills? How?

3. How do you get the participation of each member while you were in teams to learn paragraph writing through SL?

4. Have you come across any problem while learning paragraph writing through SL?

5. What do you comment to make the implementation of SL in your EFL classroom better?

\section{References}

[1] AbiyYigzaw. (2012). Impact of L1 Use in L2 English writing classes. Ethiopian Journal Education and Science, (8)1.

[2] Adeyemi, D. A. (2008). The gender factor in composition writing with the use of the cooperative and the individualized approaches at a junior secondary school in Botswana. Retrieved from http:// www.

literacy.unisa.edu.au/JEE/Papers/JEEVol8No1/Paper\%201.pdf.

[3] Ambaye Tsehaye (1999): Curriculum evaluation: Monitoring the harmony of TTI syllabus with the new primary level curriculum vis-a-vis standard models and new education and training policy. The Ethiopian Journal of Education, (19) 6.

[4] Ames, C., \& Ames, R. (1985). Research on motivation in education: Orlando: Academic Press, Inc.

[5] Booysen, M. J., \& Grosser, M. M. (2008). Enhancing social skills through cooperative learning. TD: The Journal for Trans disciplinary Research in Southern Africa, (4) 2, 377-399.

[6] Brenda, P. (1997). Teaching writing: Ask better questions-Get better writers! Instructor (Primary), 107 (4), 60-61.

[7] Brubacher, M., Payne, R., \& Rickett, K. (Eds.). (1990). Perspective on small group learning: Theory and practice. Canada: Rubicon Publishing Inc.

[8] Christopherson, M. (1994). Cooperative learning in the EFL classroom in T. Kra (ed.). Teacher development: Making the right moves. Selected Articles from the English Teaching Forum, 1989-1993. Washington English Language Program Division.

[9] Coe, R. (2002). Understanding, using and calculating effect size. Retrieved from: www.decd.sa.gov.au/quality.

[10] Cohen, J. (1988). Statistical power analysis for the behavioral sciences $\left(2^{\text {nd }}\right.$ ed.). Hillsdale, NJ: Erlbaum.

[11] Creemers, B. P. (1994). The Effective classroom. London. Redwood Books.

[12] Cuban, L. (1983). Persistence of the inevitable: The teachercentred Classroom. Education and Urban Society, 15 (26), 41.

[13] Elbow, P. (2000). Using the collage for collaborative writing. In everyone can write: Paragraphs toward a hopeful theory of writing and teaching writing. Oxford: Oxford University Press.

[14] Elis, P. D. (2010). The essential guide to effect sizes. Cambridge: Cambridge University Press.

[15] Gillies, R. M. (2007). Gillies, R. M. (2007) Cooperative learning. Integrating theory and practice. Sage Publications: Los Angeles.

[16] Guba, E. G., \& Lincoln, Y. S. (1981). Effective evaluation. San Francisco, CA: Jossey-Bass. 
[17] Hirst, B., \& Sinclair, G. (1989). Peer tutoring: A guide to learning by teaching. New York: Nichols Publishing.

[18] Howard, R. M. (2000). Collaborative pedagogy in a guide to composition pedagogies, Gary Tate et al. (eds.). Retrieved from http://dispace.nwu.ac.za/handle/10394/3970.

[19] ICDR. (1999). Teacher education hand book. Addis Ababa: Finfine Printing and Publishing.

[20] Ingleton, C., Doube, L., Nobel, A., \& Rogers, T (2000). Leap into collaborative learning. Centre for learning and professional development (CLPD). The University of Adelaide: Australia.

[21] Johnson, D. W., \& Johnson, R. T. (1987). Cooperation in schools: A conversation with David and Rodger Johnson. Educational Leadership, 45 (3), 17-18.

[22] Johnson, D. W. Johnson, R. T. and Holubec, E. J. (1993) Cooperative learning in the class- room. Alexandria: Association for supervision and curriculum development.

[23] Johnson, D. W., Johnson, R. T. (1994). The nuts and bolts of learning, Minnesota: Interaction Book Co.

[24] Khan, S. A. (2008). An experimental study to evaluate the effectiveness of cooperative learning versus traditional learning method. Unpublished PhD Dissertation. International Islamic Univer- sity: Islamabad.

[25] Kirk, T. (2005). Enhancing teaching and learning through cooperative learning. Retrieved from http://www.aect.org.Intranet/Publications/edtech/35/3504.html.

[26] Kline, F., \& Lerner, J. (2006). Learning disabilities and related disorders. Characteristics and teaching strategies (10 $0^{\text {th }}$ Edition.). Boston: Houghton Mifflin Company.

[27] Krashen, S., \&Terrell, T. D. (1983). The natural approach. Pergamon: Oxford.

[28] Lewin, K. (1948). Resolving social conflicts. New York: Harper.

[29] Leila, Z. (2010). Cooperative learning as a motivational factor in enhancing students' writing. The case of second year EFL students. Constantine University: Algeria.

[30] McConnel, D. (1994). Implementing computer supported cooperative learning. London: Kogan Page Limited.
[31] Ministry of Education. (1994). Minstry of Education. (2004). Education sector development program. Action plan. Addis Ababa: EMPDA.

[32] Moffet, J. M. (1996). Effective technique for English conversation group. Washington: USA Information Agency Performance.

[33] Richards, J. C., \& Rodgers, T. S. (2001). Approaches and methods in language teaching. Cambridge: Cambridge University Press.

[34] Schultz, A. (1999). Foreign language instruction and curriculum. The Education Digest, 64 (7), 29-37.

[35] Sirikhun, S. (2000). The use of the cooperative integrated reading and composition strategy to develop students' English writing competence. Unpublished Master's Thesis, Mahasarakham University, Thailand.

[36] Slavin, R. E. (1991). Synthesis of research on cooperative learning. Educational Leadership, (48), 71-82.

[37] Stahl, Robert, J., \& VanSickle, R. L. (1992). Cooperative learning in the social studies classroom: An invitation to social studies. Washington, DC: National Council for the Social Studies.

[38] Stenlev, J. (2003). Cooperative learning in foreign language teaching. The Copenhagen Day and Evening College of Teacher Training.

[39] Stevahn, L. \& King, J. (2005). Managing conflict constructively. Evaluation: The International Journal of Theory, Research and Practice, 11, 415-427.

[40] Stewart, D. C. (1988). Collaborative learning and composition: Boon or bane? Rhetoric Re-view, (7) 1, 58-83.

[41] Vermette, P. J. (1998). Making cooperative learning work: Student teams in 12 classrooms. Prentice Hall.

[42] Vygotsky, L. S. (1978). Mind in society. Cambridge, MA: Harvard University Press.

[43] Webb, N. M.; Kariane M. N.; Alexander, W. C. and Brenda, S. (1998). Equity issues in collaborative group assessment: Group composition and performance. American Educational Research Journal, (35) 4, 607-651.

[44] Westwood, P. (2003). Common sense methods for children with special educational needs (4th Ed.). London: Routledge Falmer. 